\title{
IMOBILIZAÇÃO DE NITROGÊNIO DA URÉIA E DO SULFATO DE AMÔNIO APLICADO EM PRÉ-SEMEADURA OU COBERTURA NA CULTURA DE MILHO, NO SISTEMA PLANTIO DIRETO(1)
}

\author{
Waldo Alejandro Ruben Lara Cabezas ${ }^{(2)} \&$ Pedro Afonso Couto $^{(3)}$
}

\section{RESUMO}

\begin{abstract}
No segundo ano de estudo, sulfato de amônio (SA) e uréia (U) marcados com ${ }^{15} \mathrm{~N}$ foram aplicados na cultura do milho, em sucessão à aveia-preta (Avena strigosa Schieb.), no sistema plantio direto, 33 dias antes e 10 dias depois da semeadura, na dose de $80 \mathrm{~kg} \mathrm{ha}^{-1}$ de $\mathrm{N}$, incorporados a 5-7 $\mathrm{cm}$ de profundidade, em sulcos espaçados de $0,8 \mathrm{~m}$, nas entrelinhas do milho. $\mathrm{O}$ objetivo foi quantificar o $\mathrm{N}$ dos fertilizantes imobilizado no solo ( ${ }^{15} \mathrm{~N}$ orgânico), no sulco de adubação, e o N recuperado na planta nos estádios de 4-5 folhas, 11-12 folhas, florescimento e colheita. O delineamento experimental foi de blocos casualizados, efetuando-se a análise de variância em esquema fatorial $2 \times 6 \mathrm{em}$ pré-semeadura (duas fontes, $U$ e $\mathrm{SA}$, em seis épocas de amostragem) e $2 \times 3$ (duas fontes em três épocas de amostragem) em cobertura, com três repetições. $O$ experimento foi realizado em Latossolo Vermelho ácrico típico fase Cerrado subcaducifólio, na Fazenda Floresta do Lobo - Pinusplan, em Uberlândia (MG). Na aplicação em pré-semeadura, a máxima imobilização foi observada aos 22 dias da aplicação do SA $\left(9,1 \mathrm{~kg} \mathrm{ha}^{-1}\right.$ ou $11,4 \%$ do $\mathrm{N}$ aplicado) e aos 11 dias da aplicação da U (46,5 $\mathrm{kg} \mathrm{ha}^{-1}$ ou $58,1 \%$ do $\mathrm{N}$ aplicado). Até a colheita, a planta (parte aérea, grãos e raiz) acumulou 66,0 e $47,9 \mathrm{~kg} \mathrm{ha}^{-1}$ de N-SA e N-U, respectivamente, correspondendo à eficiência de
\end{abstract}

\footnotetext{
(1) Financiado pelos convênios Embrapa-Petrobrás e SN- Centro de Pesquisa e Promoção de Sulfato de Amônio Ltda. Recebido para publicação em março de 2006 e aprovado em março de 2007.

(2) Pesquisador Científico nível III, SAA-APTA-DDD Pólo Regional do Noroeste Paulista. Caixa Postal 61, CEP 15500-000 Votuporanga (SP). E-mail: waldolar@terra.com.br ou waldolar@aptaregional.sp.gov.br

(3) Mestrado em Fertilidade de Solos e Nutrição de Plantas, Universidade Federal de Uberlândia - ICIAG/UFU. Trifertil Representações Ltda. Rua Duque de Caxias 450, CEP 38400-142 Uberlândia (MG). E-mail: pa.couto@terra.com.br
} 
absorção de 82,5 e 59,9 \% do $\mathrm{N}$ aplicado. Na aplicação em cobertura, a imobilização do $\mathrm{N}$ fertilizante das duas fontes foi inferior a $12,5 \%$ do $\mathrm{N}$ aplicado, em todas as fases de crescimento da planta, evidenciando que a biomassa do solo não concorreu com a planta pelo $\mathrm{N}$ fertilizante, sendo similar à quantificação realizada na safra 1999/2000. Na média das duas safras (1999/2001) e dos estádios de 11-12 folhas e florescimento, para cada $\mathrm{kg}$ de $\mathrm{N}$ fertilizante imobilizado, as plantas de milho absorveram 8,9 e $15,4 \mathrm{~kg} \mathrm{ha}^{-1}$ de N-SA, em pré-semeadura e cobertura, respectivamente. Para $\mathrm{N}-\mathrm{U}$, esses valores foram, respectivamente, de 4,5 e $5,2 \mathrm{~kg} \mathrm{ha}^{-1}$, mostrando menor proporção de $\mathrm{N}$-imobilizado de $\mathrm{SA}$, com a aplicação dos fertilizantes em cobertura. As produtividades de grãos obtidas com SA e U, independentemente da época de aplicação, foram de 8.543 e $7.767 \mathrm{~kg} \mathrm{ha}^{-1}$, respectivamente. Na adubação em pré-semeadura do milho, o SA apresentou maior rapidez na ciclagem do $\mathrm{N}$ imobilizado-mineralizado (turnover), em relação a $\mathrm{U}, \mathrm{e}$, conseqüentemente, causou maior absorção do $\mathrm{N}$ pela cultura, como verificado na safra anterior. Em cobertura, no sulco de adubação, de forma similar à observada na safra anterior, somente houve imobilização significativa do $\mathrm{N}-\mathrm{U}$, retardando sua absorção pela planta.

Termos de indexação: biomassa de solo, isótopo ${ }^{15} \mathrm{~N}$, razão $\mathrm{N}$ fertilizante planta/ $\mathrm{N}$ fertilizante imobilizado, $\mathrm{N}$-imobilizado-N mineralizado.

\section{SUMMARY: NITROGEN IMMOBILIZATION OF UREA AND AMMONIUM SULPHATE APPLIED TO MAIZE BEFORE PLANTING OR TOP- DRESSING IN A NO-TILL SYSTEM}

Ammonium sulfate (AS) and urea (U), labeled with ${ }^{15} \mathrm{~N}$, were applied to no-till maize, 33 days before and 10 days after sowing, at a single rate of $80 \mathrm{~kg} \mathrm{ha}^{-1}$ of $\mathrm{N}$ incorporated 5$7 \mathrm{~cm}$ deep along furrows spaced $0.8 \mathrm{~m}$. Corn was sown after black oat (Avena strigosa Schieb.).The amount of immobilized $N$ and of $N$-fertilizer recovered by corn plants was evaluated at the following plants stages: 4-5 leaves, 11-12 leaves, flowering, and at harvest. Treatments were applied in a randomized block design with three replications. The analysis of variance was performed based on one factorial scheme $(2 \times 6)$ with two sources in preplanting ( $A S$ and $U$ ) on six sampling dates, and on a second $(2 \times 3)$ with two sources in topdressing on three sampling dates. This field experiment was carried out on a Typic Acrustox in Uberlandia, Minas Gerais state, Brazil. Pre-planting applications resulted in a maximal AS-N immobilization 22 days after fertilizer application $\left(9.1 \mathrm{~kg} \mathrm{ha}^{-1}\right.$ or $11.4 \%$ of applied $N)$, whereas the maximum immobilization of $U-N$ occurred 11 days after fertilizer application $\left(46.5 \mathrm{~kg} \mathrm{ha}^{-1}\right.$ or $58.1 \%$ of applied N). Until harvest, the plants (aerial part, grains and roots) had accumulated 66.0 and 47.9 of $A S-N$ and $U-N$, respectively (use efficiency of 82.5 and $59.9 \%$ of applied $N$ ). $N$ top-dressing resulted in $12.5 \%$ less $N$ immobilized applied as both sources in all growth stages, evidencing that the soil biomass did not compete with the plants for $N$-fertilizer, in agreement with results of the growing season 1999/2000. In both growing seasons (1999/2000 and 2000/2001) corn plants assimilated an average 8.9 and $15.4 \mathrm{~kg} \mathrm{ha}^{-1}$ of $A S-N$ for each $\mathrm{kg}$ of immobilized $N$-fertilizer from pre-planting and top-dressing, respectively, in the stage of 11-12 leaves and at flowering. For $U-N$ these values were 4.5 and $5.2 \mathrm{~kg} \mathrm{ha}^{-1}$, respectively, presenting a lower ratio of immobilized $A S-N$ in top-dressing. Highest corn yields were obtained in the $A S$ treatments (mean grain yield of $8.543 \mathrm{~kg} \mathrm{ha}^{-1}$ ) independent of the application time. Urea treated plants obtained average grain yields of $7.767 \mathrm{~kg} \mathrm{ha}^{-1}$ for both application periods. These results show that for pre-planting fertilizers the immobilization-mineralization $N$ turnover was faster in the AS than in the U-N treatment. Consequently, $N$ assimilation by corn plants was higher in the AS treatments. Only $U-N$ was significantly immobilized more also in the second growing season when top-dressed, thus limiting plant $N$ uptake.

Index terms: soil biomass, ${ }^{15} \mathrm{~N}$ isotope, ratio of fertilizer- $\mathrm{N}$ in plant /immobilized fertilizer$N, N$-immobilized $N$, mineralized $N$. 


\section{INTRODUÇÃO}

A aplicação de N no solo está sujeita a perdas por volatilização, imobilização, denitrificação e lixiviação e sua eficiência de utilização pela planta está regulada por fatores de solo, climáticos, tipo de cultura e de fertilizante e suas práticas de manejo. Segundo Malhi et al. (2001), em geral, a eficiência de recuperação de $\mathrm{N}$ aplicado é inferior a $50 \%$ em solos tropicais; em sistema plantio direto (SPD), há mudanças na demanda de $\mathrm{N}$ pela cultura devido à mudança do potencial produtivo e da disponibilidade pelo solo em razão da ciclagem de $\mathrm{N}$ e suas perdas. Em conseqüência, a eficiência de recuperação de $\mathrm{N}$ do fertilizante é alterada, com mudanças no preparo de solo, microclima, atividade microbiana e distribuição do fertilizante em relação à resteva em superfície. A localização em faixa reduz o contato com a biomassa de solo e diminui a hidrólise da uréia, reduzindo as perdas por denitrificação e lixiviação.

Em SPD estabelecido, a imobilização de $\mathrm{N}$ pela biomassa de solo constitui um dreno importante de N, de caráter transitório. Um conhecimento aprofundado do processo, aliado a práticas de manejo adequadas, pode-se traduzir em benefício para o sistema soloplanta, contornando-se a indisponibilidade na época de maior demanda de N pela cultura. Segundo Hasada et al. (1992), a imobilização de $\mathrm{N}$ pela biomassa durante a decomposição da resteva ocorre de forma direta, pela imobilização de substratos nitrogenados orgânicos de baixo peso molecular (ex.: aminoácidos), e de forma indireta, pela imobilização de $\mathrm{N}$ mineral após a mineralização de $\mathrm{N}$ orgânico. A ocorrência favorável à mineralização ou imobilização é influenciada por diversos fatores, como: temperatura, umidade, presença de $\mathrm{O}_{2}$, biomassa de solo e os conteúdos de $\mathrm{C}$ e $\mathrm{N}$ do material orgânico adicionado ao solo (Lopes et al., 2004). Na imobilização, o $\mathrm{NH}_{4}{ }^{+}$ é preferencialmente utilizado pela biomassa de solo (Jansson et al., 1955; Broadbent \& Tyler, 1965; Recous et al., 1988), em detrimento do $\mathrm{NO}_{3}-$. O aumento de $\mathrm{pH}$ no solo favorece maior imobilização de $\mathrm{N}-\mathrm{NH}_{4}{ }^{+}$ (Broadbent \& Tyler, 1965). A imobilização ocorre quando a relação C:N excede valores de 20:1 a 25:1 (Sims, 1990; Burgess et al., 2002; Lopes et al., 2004). No Cerrado ainda são incipientes as áreas com SPD estabelecidas e bem conduzidas, motivo pelo qual esse processo ainda não deve ser relevante. Â medida que o SPD venha a ser o sistema tradicional de semeadura, a imobilização deverá ser importante, em razão da diversidade e do aumento da biomassa de solo (Doran, 1980). Em relação a esse processo e à falta de conhecimento deles em condições tropicais, os resultados publicados por Sá (1996), em solos do Paraná, na sucessão aveia-preta-milho foram muito importantes, uma vez que a aplicação em présemeadura de $\mathrm{N}$ no milho estaria contornando a imobilização, em relação à aplicação em cobertura, e facilitando a operacionalidade de uso de maquinário.
A antecipação da aplicação de $\mathrm{N}$ sobre resteva de aveiapreta estaria estimulando a imobilização para sua posterior disponibilidade à cultura. A aplicação de $\mathrm{N}$ em cobertura, por sua vez, poderia gerar concorrência do $\mathrm{N}$ entre a planta e a biomassa de solo. Estudos posteriores mostraram resultados diferentes dos obtidos por Sá (Basso \& Ceretta, 2000; Pottker \&Wietholter, 2004). Lopes et al. (2004) afirmam que, para se ter sucesso, a aplicação de $\mathrm{N}$ em présemeadura de milho requer solos com vários anos de adoção do SPD, com acúmulo de MO pelo sistema de rotação estabelecido, gerando considerável liberação e disponibilidade de $\mathrm{N}$, em anos com chuvas de intensidade regular e em solos de textura média ou argilosa.

Neste estudo (segundo ano) foi quantificado o $\mathrm{N}$ imobilizado no sulco de adubação, ao longo do ciclo fenológico da cultura de milho, dos fertilizantes uréia (U) e sulfato de amônio (SA) aplicados em présemeadura e cobertura, em relação à absorção pela cultura do milho em solo muito argiloso e seus efeitos na produtividade em SPD, sequeiro, em condições edafoclimáticas do Triângulo Mineiro, MG.

\section{MATERIAL E MÉTODOS}

Este experimento constitui uma repetição (segundo ano) do realizado na safra 1999-2000 (Lara Cabezas et al., 2005) na Fazenda Floresta do Lobo-Pinusplan, BR 050, km 93, no município de Uberlândia (MG), entre abril de 2000 e março de 2001, cultivando-se aveia-preta (Avena strigosa Schieb.) no inverno e o híbrido simples, precoce, Tork (Syngenta), em sucessão. A área em SPD foi cultivada com soja e milho alternadamente desde 1997/98, com sorgo granífero no inverno de 1998, pousio (inverno de 1999) e aveia-preta no inverno de 2000, apresentando produtividades médias de 2.850 e $6.780 \mathrm{~kg} \mathrm{ha}^{-1}$ para soja e milho, respectivamente.

Em 20/4/2000, foi semeada aveia-preta (cultivar IAPAR 61, com 81,9 \% de valor cultural) na área total do talhão, numa densidade de $17,0 \mathrm{~kg} \mathrm{ha}^{-1}$ de sementes, com espaçamento de $0,5 \mathrm{~m}$, sem adubação. A cultura foi manejada com rolo-faca em 5/10/2000, 167 dias após a semeadura, efetuando-se antes do manejo a determinação de massa de matéria seca (MMS) produzida em quadrante de $1 \mathrm{~m}^{2}$, lançado ao acaso na área experimental a intervalos de 20 a 30 dias durante o ciclo da cultura, em quadruplicata. A determinação de MMS e o cálculo da relação C:N foram similares aos utilizados por Lara Cabezas et al. (2005).

O Latossolo Vermelho ácrico típico fase Cerrado subcaducifólio (Embrapa, 1999) foi analisado nas camadas de 0-10 e 10-20 cm (Quadro 1). A amostragem de solo efetuada em setembro de 2000 seguiu o critério adotado por Lara Cabezas et al. (2005). 
Quadro 1. Caracterização da fertilidade das amostras de solo utilizadas no experimento(1)

\begin{tabular}{|c|c|c|c|c|c|c|c|}
\hline Profundidade & $\mathrm{pH}\left(\mathrm{H}_{2} \mathbf{0}\right)$ & $\mathbf{P}$ & $\mathbf{K}$ & S-sulfato & СтC & $\mathbf{V}$ & MO \\
\hline $\mathrm{cm}$ & $1: 2,5$ & $\ldots$ & $\mathrm{mg} \mathrm{dm}^{-3}$ & 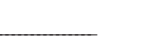 & $\mathrm{mmol}_{\mathrm{c}} \mathrm{dm}^{-3}$ & $\%$ & $\mathrm{~g} \mathrm{dm}^{-3}$ \\
\hline $00-10$ & 5,4 & 15,8 & 117,3 & 2,0 & 62,0 & 50,0 & 44,0 \\
\hline $10-20$ & 5,2 & 26,0 & 39,1 & 6,0 & 61,0 & 33,0 & 38,0 \\
\hline
\end{tabular}

(1) $\mathrm{P}$ e K (extrator Mehlich-1). $\mathrm{S}=$ solução extratora $\mathrm{Ca}\left(\mathrm{H}_{2} \mathrm{PO}_{4}\right)_{2}$ 0,01 mol L'- MO = colorimetria com dicromato de sódio 0,667 mol L-1. CTC a pH 7,0 segundo Raij et al. (2001).

Previamente à semeadura do milho, 20 dias antes, foi feita adubação de $60 \mathrm{~kg} \mathrm{ha}^{-1} \mathrm{de} \mathrm{K}_{2} \mathrm{O}(\mathrm{KCl})$, a lanço, sem incorporação, como efetuado no restante da área comercial. O híbrido simples Tork, precoce, foi semeado em 11/11/2000, com espaçamento de $0,8 \mathrm{~m}$, numa densidade de 62.500 sementes por hectare. No sulco de semeadura, na área comercial e nos tratamentos descritos a seguir, realizou-se a aplicação de $45,5,105,0$ e $28 \mathrm{~kg} \mathrm{ha}^{-1}$ de $\mathrm{N}, \mathrm{P}_{2} \mathrm{O}_{5}$ e $\mathrm{K}_{2} \mathrm{O}$ nas formas de $\mathrm{NH}_{4} \mathrm{NO}_{3}$, MAP e $\mathrm{KCl}$, respectivamente, e de 0,49 e $0,22 \mathrm{~kg} \mathrm{ha}^{-1}$ de $\mathrm{B}$ e $\mathrm{Mn}$, respectivamente. Durante o ciclo da cultura, realizou-se o controle químico de plantas daninhas e lagarta elasmo, como no restante da área comercial.

A colheita foi realizada em 2/4/2001. Nas quatro linhas centrais de cada parcela, colheram-se manualmente espigas, num comprimento de $10 \mathrm{~m}$ cada, sendo determinada a população efetiva de plantas e a produtividade de grãos (umidade corrigida para $130 \mathrm{~g} \mathrm{~kg}^{-1}$ ). O acompanhamento das temperaturas máximas e mínimas médias e da pluviosidade foi efetuado durante todo o período experimental.

Utilizou-se delineamento de blocos casualizados, em esquema fatorial $2 \times 6$, em triplicata, com dois tratamentos de fontes [sulfato de amônio (SA) uréia (U)], e seis épocas de amostragem para as fontes aplicadas em pré-semeadura e em esquema 2 x 3 para as duas fontes, com amostragem em três épocas fenológicas em cobertura. A decisão de adotar a dose de $80 \mathrm{~kg} \mathrm{ha-1}$ de $\mathrm{N}$ como adubação suplementar à base foi a utilizada pelo produtor rotineiramente na cultura de milho. Assim, os tratamentos de fontes, considerando essa dose, foram: (1) testemunha, sem aplicação de N em pré-semeadura ou cobertura; (2) U aplicada em pré-semeadura (33 dias antes), incorporada com haste escarificadora na profundidade de $5-7 \mathrm{~cm}$ de profundidade, no meio das futuras entrelinhas; (3) U aplicada em cobertura (estádio de 4-5 folhas) no meio das entrelinhas; (4) SA em présemeadura (33 dias antes) e (5) SA em cobertura, nas mesmas condições citadas anteriormente.

Cada parcela (fonte-época) ficou constituída de 14 linhas, espaçadas de 0,8 e $30 \mathrm{~m}$ de comprimento. Dentro de cada parcela correspondente aos tratamentos de U e SA em pré-semeadura, foram instaladas, aleatoriamente, cinco subparcelas de
1,0 x 1,6 m, abrangendo o sulco de adubação e duas linhas adjacentes de plantas, onde foi substituído o adubo comercial por fertilizantes enriquecidos $\operatorname{com}^{15} \mathrm{~N}$ [U (46,8\% de N) com 4,86 $\pm 0,01 \%$ e SA (21,4\% de $\mathrm{N})$ com 5,01 $\pm 0,01 \%$ em abundância de ${ }^{15} \mathrm{~N}$, aplicados manualmente. Essas subparcelas, como no estudo anterior, foram utilizadas para quantificar o $\mathrm{N}$ imobilizado proveniente do fertilizante (Nispf) e o N na planta proveniente do fertilizante (Nppf) do sulco de adubação. Em pré-semeadura, as amostragens foram realizadas após 11 e 22 dias de aplicação dos adubos e aos 44, 79, 95 e 173 dias, correspondentes aos estádios de 4-5 folhas, 11-12 folhas, florescimento e colheita, respectivamente. Nos tratamentos de cobertura, as amostragens foram realizadas aos 35 , 51 e 129 dias depois de aplicação da fontes, correspondendo aos estádios de 11-12 folhas, florescimento e colheita, respectivamente.

O Nispfrepresentou o N orgânico proveniente do $\mathrm{N}$ fertilizante assimilado pela biomassa de solo, sendo calculado de forma indireta, para cada época, segundo a expressão $N i s p f=N t$ spf $-N$ mispf, em que $N t$ spf $=$ $\mathrm{N}$ total no solo proveniente do fertilizante e Nmispf $=$ $\mathrm{N}$ mineral no solo proveniente do fertilizante, como descrito por Francis et al. (1993). O tratamento das amostras de solo, obtidas das entrelinhas, no sulco de adubação, de cada tratamento e a determinação de $\mathrm{N}$ total, $\mathrm{N}$ mineral total e as concentrações de ${ }^{15} \mathrm{~N}$ foram efetuados a partir de amostras de terra coletadas num volume de $5 \mathrm{dm}^{3}(50 \times 10 \times 10 \mathrm{~cm}$ de comprimento, largura e profundidade, respectivamente), efetuandose quarteio e transporte de amostras de aproximadamente $0,5 \mathrm{~kg}$ ao laboratório e conservandoas a $-18,0^{\circ} \mathrm{C}$. As amostras foram preparadas como indicado por Lara Cabezas et al. (2005) e acondicionadas em saco plástico para envio ao CENA/ USP, Piracicaba (SP), para análise do teor de $\mathrm{N}$ total e determinação da concentração de ${ }^{15} \mathrm{~N}$ por espectrometria de massas (ANCA modelo SL, 20-20, da Europa Scientific Barrie \& Prosser (1996)). Os cálculos da concentração ( \%) e da quantidade do Ntspf e do Nmispf foram efetuados de acordo com as seguintes expressões:

$$
N t(m i) s p=100(\mathrm{~A}-\mathrm{C}) /(\mathrm{B}-\mathrm{C})
$$

$N t(m i)_{s p f}=\left[(N t(m i)\right.$ spf $/ 100] N t(m i)_{s p f}$ 
em que $\mathrm{A}=$ concentrações de ${ }^{15} \mathrm{~N}$ ( \% em abundância em átomos de ${ }^{15} \mathrm{~N}$ ) no $N$ tspf e Nmispf; $\mathrm{B}=$ concentração de ${ }^{15} \mathrm{~N}$ do fertilizante e $\mathrm{C}=$ concentração isotópica natural do solo $(0,366$ \% de abundância em átomos de $\left.{ }^{15} \mathrm{~N}\right)$, respectivamente. Os cálculos, expressos em $\mathrm{kg} \mathrm{ha}^{-1}$, foram relativos ao volume de $125 \mathrm{~m}^{3}(\{0,005 \times 12.500\} / 0,5)$, abrangido pelo fertilizante na entrelinha, em um hectare. No cálculo, foi considerada a densidade média aparente do sulco, de $1,20 \mathrm{~kg} \mathrm{dm}^{-3}$, determinada pelo método do anel volumétrico. O Nispffoi expresso também como \% do $\mathrm{N}$ aplicado $\left(80 \mathrm{~kg} \mathrm{ha}^{-1}\right)$. Todos os valores foram referidos com base em solo seco em estufa a $105^{\circ} \mathrm{C}$ até peso constante.

Nas mesmas épocas definidas para determinação de Nispf, amostras de solo foram separadas para obtenção de TFSA, em triplicata, de cada tratamento, a fim de determinar o $\mathrm{pH}\left(\mathrm{H}_{2} 0\right)$ na razão 1:2,5 e acompanhar a variação após a aplicação dos adubos.

Na determinação do Nppf, foram efetuadas, nas subparcelas, amostragens de plantas (5-7), cortadas a $5 \mathrm{~cm}$ da superfície do solo. O Nppffoi determinado por espectrometria de massa e calculado como indicado nas equações 1 e 2 . A expressão em $\mathrm{kg} \mathrm{ha}^{-1}$ do $N p p f$ considerou a média das plantas coletadas na microparcela. Os valores de Nppfforam multiplicados pelo fator 2, em decorrência do modelo empregado, ou seja, marcação de um segmento de sulco de $1 \mathrm{~m}$ com fertilizante ${ }^{15} \mathrm{~N}$ e colheita das plantas nas linhas imediatamente adjacentes.

Após a análise de variância em esquema fatorial, aplicou-se o teste de Tukey a $5 \%$, para comparar as fontes em cada época e diferentes épocas dentro de cada fonte.

\section{RESULTADOS E DISCUSSÃO}

\section{Manejo da aveia-preta como cultura antecessora}

A produção de aveia-preta foi de $0,48 \mathrm{t} \mathrm{ha}^{-1}$ de MMS após 135 dias da semeadura, acumulando em média 9,8 kg ha-1 de $\mathrm{N}$ total e com relação C:N da parte aérea de 21,4 (Figura 1). Aos 93 dias após semeadura, houve pastejo animal acidental, mostrando-se a queda na relação $\mathrm{C}: \mathrm{N}$ devido à rebrota da cultura com o início da precipitação ocorrida em setembro de 2000. Portanto, considerando-se que a imobilização requer a presença de resíduos acima de 30:1 de C:N (Lopes et al., 2004), nas condições deste estudo, a biomassa não teria estado submetida à falta de $\mathrm{N}$.

Em relação ao ano anterior, com produção de 1,1 $\mathrm{t} \mathrm{ha}^{-1}$ de MMS e 13,2 $\mathrm{kg} \mathrm{ha}^{-1}$ de N (Lara Cabezas et al., 2005), a produção de MMS foi a metade e o N acumulado foi similar. Esses resultados salientam o cuidado que se deve ter ao importar culturas de outras regiões do País, visando obter as vantagens de outras localidades. Segundo Floss (2002), a avaliação de MMS de diversos cultivares de aveia-preta entre 1992 e 1996 em Passo Fundo-RS, com manejo em plena
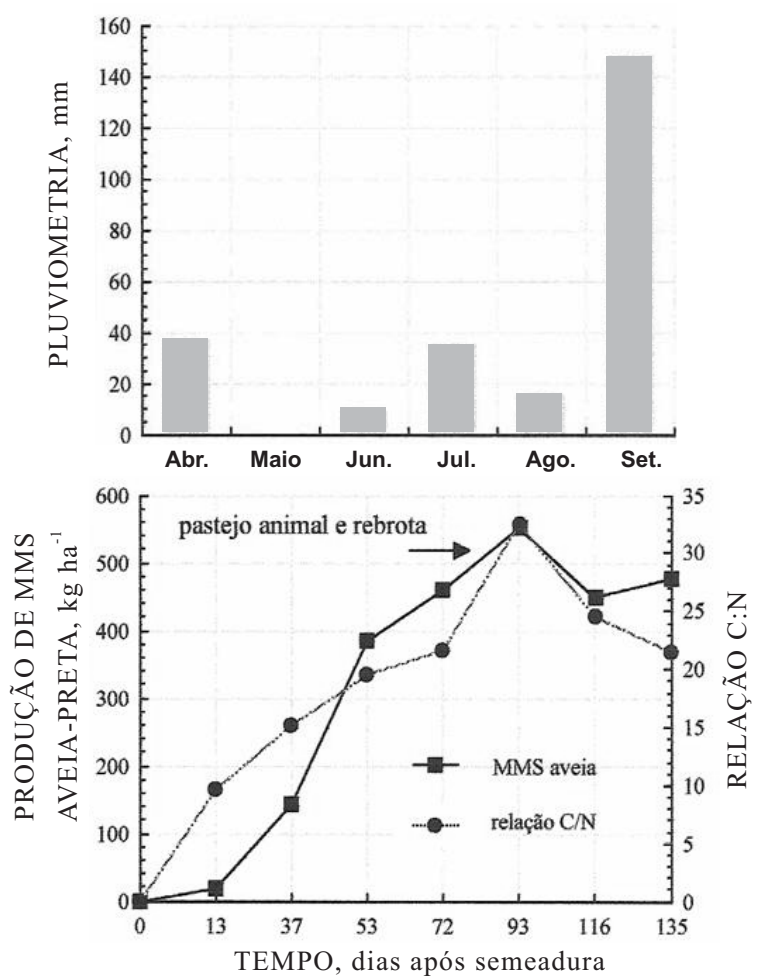

Figura 1. Precipitação pluvial mensal, marcha de produção de massa de matéria seca (MMS) e relação $\mathrm{C}: \mathrm{N}$ da parte aérea de aveia-preta nos meses de outono-inverno de 2000 , como cultura antecessora ao milho.

floração, foi em média de 6,6 $\mathrm{Mg}_{\mathrm{ha}} \mathrm{h}^{-1}$ de MMS - valores esses superiores aos obtidos por produtores da região do Triângulo Mineiro. Esses resultados refletem, entretanto, a realidade do produtor, que não está fazendo cobertura para o inverno em SPD. Esses resultados refletem, entretanto, a realidade do produtor, que não está fazendo cobertura para o inverno em SPD. Nesse sentido, a modalidade Santa Fé em SPD e suas variações estão mostrando que o Cerrado apresenta soluções próprias para enfrentar condições climáticas diferentes daquelas do Sul do País (Oliveira et al., 2001). Cabe salientar que no Sul há maior leque de espécies para sua inserção no SPD, como aveia-branca, cevada, colça, ervilhaca, linho, milho, soja, serradela, tremoço, trigo e trevo-vesiculoso (Santos et al., 1999).

N-imobilizado no solo (Nispf) e N-planta proveniente do fertilizante $(N p p f)$ aplicado em pré-semeadura na cultura de milho

Houve tendência de diminuição do $\mathrm{N}$ total do solo no sulco de adubação em ambas as fontes, como conseqüência da provável mineralização de N-MO e absorção pela planta e do deslocamento do $\mathrm{N}$ fertilizante para a subsuperficie (Quadro 2). Quantidades apreciáveis de Ntspf foram observadas até os 22 dias após aplicação das fontes, diminuindo notadamente 
nos estádios de 4-5 folhas, 11-12 folhas, florescimento e colheita. Até os 22 dias da aplicação, o NtspSA (40,3 $\mathrm{kg} \mathrm{ha}^{-1}$ ) ficou preferencialmente na forma mineral $(77,5 \%)$ e $22,5 \%$ na forma de Nispf. Aos 44 dias após semeadura (DAS) (estádio de 4-5 folhas), somente $12,9 \mathrm{~kg} \mathrm{ha}^{-1}$ foram determinados no sulco como $N$ tspf, sendo nessa época $9,2 \mathrm{~kg} \mathrm{ha}^{-1}(11,5 \%$ do $\mathrm{N}$ aplicado) como NispSA e somente $3,7 \mathrm{~kg} \mathrm{ha}^{-1}(4,6 \%$ do $\mathrm{N}$ aplicado) como NminspSA. Houve, portanto, predomínio de $\mathrm{N}$ fertilizante imobilizado sobre a forma mineral, perdendo sua importância nos estádios mais avançados da cultura, e o $\mathrm{N}$-imobilizado predominou na forma estabilizada. Em relação à aplicação de U, houve imobilização do $\mathrm{N}$ de $46,5 \mathrm{~kg} \mathrm{ha}^{-1}$ aos 11 dias de aplicação (58,1\% do $\mathrm{N}$ aplicado), diminuindo rapidamente até $5,4 \mathrm{~kg} \mathrm{ha}^{-1}$ aos 22 dias de aplicação, predominando o $\mathrm{N}$ fertilizante na forma mineral (26,6 $\left.\mathrm{kg} \mathrm{ha}^{-1}\right)$, quando a cultura não estava ainda estabelecida. Nas fases ulteriores, o comportamento foi similar ao observado para o N-SA. Em solo incubado em vasos, nas etapas iniciais de decomposição de resteva a maior parte do ${ }^{15} \mathrm{~N}$ mineral foi imobilizada pela biomassa de solo (Jawson \& Elliot, 1986); em condições de campo, Jackson et al. (1989) demonstraram que mais de um terço do $\mathrm{N}$ mineral aplicado foi recuperado na fração microbiana após $24 \mathrm{~h}$ de aplicado, em solos de pastagens na Califórnia-EUA. Moritsuka et al. (2004), incubando solo com resíduos de arroz e folhas de leguminosas, verificaram na interfase solo-resíduo aumento significativo de Nmicrobiano até $10 \mathrm{~mm}$ da interfase com a palha de arroz e insignificante com as folhas, cinco dias após a incubação, sendo a seguir rapidamente excedida a taxa de mineralização em relação à imobilização, aos 15 e 30 dias após a incubação, mostrando haver grande dinâmica na transformação de N.

A escassa contribuição da aveia-preta em MMS como cobertura morta mostrou que a imobilização decresceu rapidamente logo após a aplicação das fontes (Figura 2). O restrito fornecimento de $\mathrm{C}$ como fonte energética para a biomassa de solo deve ter afetado a imobilização de N fertilizante. Por sua vez, o priming effect devido à aplicação das fontes deve ter acentuado a mineralização de $\mathrm{N}-\mathrm{MO}$ e, conseqüentemente, disponibilizado $\mathrm{N}$ ao sistema. Aos 40 DAA. ambas as fontes apresentaram valores inferiores a $20 \mathrm{~kg} \mathrm{ha}^{-1}$ de Nispf nos dois anos de estudo, inferior a $25 \%$ do $\mathrm{N}$ aplicado, mostrando que a falta de cobertura não beneficiou a retenção temporária de $\mathrm{N}$ fertilizante na subsuperfície de solo, para sua posterior transferência

Quadro 2. N total do solo proveniente do fertilizante (Ntspf), N mineral do solo proveniente do fertilizante (Nmispf), $\mathrm{N}$-imobilizado no solo proveniente do fertilizante (Nispf) e fração do $\mathrm{N}$ fertilizante imobilizado após a aplicação em pré-semeadura de sulfato de amônio e uréia, para a cultura do milho, em sistema plantio direto $^{(1)}$

\begin{tabular}{|c|c|c|c|c|c|c|c|c|c|c|}
\hline \multirow{2}{*}{ Época (estádio) } & \multirow{2}{*}{ N-total } & \multirow{2}{*}{$\begin{array}{c}\text { Concentração } \\
\text { de }{ }^{15} \mathrm{~N}\end{array}$} & \multicolumn{2}{|c|}{ Ntspf } & \multirow{2}{*}{$\begin{array}{c}\text { N-min. } \\
\text { Total }\end{array}$} & \multirow{2}{*}{$\begin{array}{c}\text { Concentração } \\
\text { de }{ }^{15} \mathrm{~N}\end{array}$} & \multicolumn{2}{|c|}{ Nminspf } & \multicolumn{2}{|c|}{ Nispf } \\
\hline & & & Concentração & Conteúdo & & & Concentração & Conteúdo & Concentração & Conteúdo \\
\hline $\mathrm{DAA}^{(2)}$ & $\mathrm{kg} \mathrm{ha}^{-1}$ & atom. \% excesso & $\%$ & $\ldots \mathrm{kg} \mathrm{h}$ & $\mathrm{a}^{-1}$ & atom. \% excesso & $\%$ do aplicado & $\mathrm{kg} \mathrm{ha}^{-1}$ & $\%$ do aplicado & $\mathrm{kg} \mathrm{ha}^{-1}$ \\
\hline \multicolumn{11}{|l|}{ Sulfato de Amônio } \\
\hline 11 & $283 \mathrm{aA}$ & 1,115 & 24,0 & 67,9 aA & $49,9 \mathrm{aA}$ & 3,944 & 84,9 & 42,4 aA & 31,9 & $25,5 \mathrm{bA}$ \\
\hline 22 & $224 \mathrm{aBC}$ & 0,836 & 18,0 & $40,3 \mathrm{aB}$ & $19,6 \mathrm{bB}$ & 3,599 & 77,5 & $15,2 \mathrm{bB}$ & 31,4 & $25,1 \mathrm{aA}$ \\
\hline 44 (4-5 folhas) & $268 \mathrm{abA}$ & 0,223 & 4,8 & $12,9 \mathrm{aC}$ & $8,8 \mathrm{aB}$ & 1,953 & 42,1 & 3,7 aBC & 31,5 & $9,2 \mathrm{aAB}$ \\
\hline 79 (11-12 folhas) & $207 \mathrm{bCD}$ & 0,098 & 2,1 & $4,3 \mathrm{bD}$ & $1,9 \mathrm{aB}$ & 0,209 & 4,5 & $0,1 \mathrm{aC}$ & 5,3 & $4,2 \mathrm{aB}$ \\
\hline 95 (florescimento) & $171 \mathrm{aD}$ & 0,107 & 2,3 & $3,9 \mathrm{aD}$ & $2,3 \mathrm{aB}$ & 0,216 & 4,7 & $0,1 \mathrm{aB}$ & 4,8 & $3,8 \mathrm{aB}$ \\
\hline 173 (colheita) & $190 \mathrm{aCD}$ & 0,065 & 1,4 & $2,7 \mathrm{aD}$ & $2,9 \mathrm{aB}$ & 0,099 & 2,1 & $0,1 \mathrm{aB}$ & 3,3 & $2,6 \mathrm{aB}$ \\
\hline \multicolumn{11}{|l|}{ Uréia } \\
\hline 11 & $294 \mathrm{aA}$ & 1,061 & 23,6 & 69,4 aA & $29,1 \mathrm{bAB}$ & 3,531 & 78,6 & $22,9 \mathrm{bA}$ & 58,1 & 46,5 aA \\
\hline 22 & $212 \mathrm{aB}$ & 0,679 & 15,1 & $32,9 \mathrm{bB}$ & $44,0 \mathrm{aA}$ & 2,720 & 60,5 & 26,6 aA & 6,8 & $5,4 \mathrm{bB}$ \\
\hline 44 (4-5 folhas) & $198 \mathrm{bB}$ & 0,180 & 4,0 & $7,9 \mathrm{bC}$ & $12,2 \mathrm{aBC}$ & 0,057 & 1,3 & $1,8 \mathrm{aB}$ & 7,6 & $6,1 \mathrm{aB}$ \\
\hline 79 (11-12 folhas) & $266 \mathrm{aA}$ & 0,130 & 2,9 & $7,7 \mathrm{aC}$ & $4,1 \mathrm{aC}$ & 0,334 & 7,4 & $0,3 \mathrm{aB}$ & 9,3 & $7,4 \mathrm{aB}$ \\
\hline 95 (florescimento) & $165 \mathrm{aB}$ & 0,103 & 2,3 & $3,8 \mathrm{aC}$ & $4,4 \mathrm{aC}$ & 0,130 & 2,9 & $0,1 \mathrm{aB}$ & 4,6 & $3,7 \mathrm{aB}$ \\
\hline 173 (colheita) & $205 \mathrm{aB}$ & 0,1 & 2,6 & $5,3 \mathrm{aC}$ & $2,7 \mathrm{aC}$ & 0,191 & 4,3 & $0,1 \mathrm{aB}$ & 6,5 & $5,2 \mathrm{aB}$ \\
\hline $\begin{array}{l}\text { DMS (entre fontes } \\
\text { para cada época) }\end{array}$ & 35,2 & & & 21,5 & 13,1 & & & 10,0 & & 11,2 \\
\hline $\begin{array}{l}\text { DMS (entre épocas } \\
\text { para cada fonte) }\end{array}$ & 52,7 & & & 8,5 & 19,5 & & & 14,9 & & 16,8 \\
\hline $\mathrm{CV}(\%)$ & 9,4 & & & 8,5 & 51,1 & & & 62,6 & & 55,4 \\
\hline
\end{tabular}

(1) As médias entre épocas para cada fonte, seguidas de letras maiúsculas iguais, não diferem significativamente pelo teste de Tukey a $5 \%$. As médias entre fontes para cada época, seguidas de letras minúsculas desiguais, diferem significativamente pelo teste de Tukey a $5 \%$. ${ }^{(2)} \mathrm{DAA}=$ dias após aplicação de sulfato de amônio e uréia. 

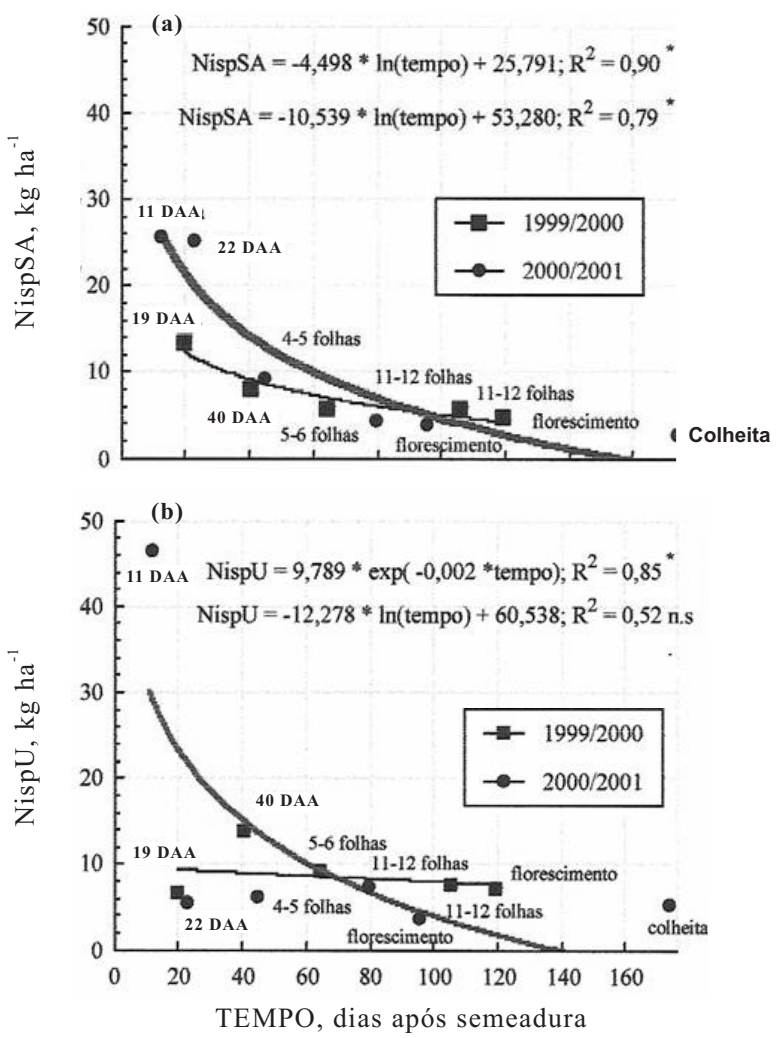

Figura 2. Nitrogênio imobilizado no solo de sulfato de amônio (NispSA) (a) e da uréia (NispU) (b), aplicado em pré-semeadura na entrelinha das futuras fileiras de plantas de milho, em duas safras consecutivas (1999-2001), em sistema plantio direto. (DAA = dias após adubação).

à cultura instalada. Num sistema em implantação, ainda sem cobertura de solo consolidada, evidencia-se a importância de instalar uma cultura cedo (no pó), no início da primavera (ex.: milheto), como alternativa para reter o $\mathrm{N}$ aplicado antecipado ou favorecer a rebrota de material remanescente no campo (ex.: sorgo). O solo do experimento apresenta condições para suprir o N via mineralização da $\mathrm{MO}$, segundo a caracterização apresentada, visto que ensaios anteriores com adubação antecipada não mostraram diferença de produtividade em milho, em relação ao fertilizante aplicado em cobertura. A melhoria na retenção do $\mathrm{N}$ aplicado passa por uma cobertura de solo mais adensada, para favorecer o processo de imobilização e consolidar o conceito de adubação de sistema, com posterior aproveitamento na cultura em sucessão (Lara Cabezas \& Lange, 2003).

$\mathrm{N}$-planta proveniente do fertilizante ( $N p p f)$, eficiência de utilização de $\mathrm{N}$-planta proveniente do fertilizante (EUNppf) e eficiência de recuperação de N-planta proveniente do fertilizante (ERNppf) aplicado em pré-semeadura na cultura de milho

No estádio de $4-5$ folhas, quantidades insignificantes de $\mathrm{N}$ fertilizante foram recuperadas na planta (dados não mostrados). Até o estádio de 11-12 folhas, houve acúmulo de $\mathrm{N}$ fertilizante na planta: 39,9 e $29,8 \mathrm{~kg} \mathrm{ha}^{-1}$ de N-SA e N-U, respectivamente, representando 49,9 e 37,3\% do N aplicado [(Nppf/ Nfa) x 100] (Figura 3). Neste estádio ficou definida a maior recuperação pela planta do N-SA em relação a N-U. Nos estádios ulteriores, até a colheita, continuou o acúmulo decrescente de $\mathrm{N}$ fertilizante, sendo de 66,0 e $47,9 \mathrm{~kg} \mathrm{ha}^{-1}$ de N-SA e N-U, respectivamente. A eficiência de recuperação de $\mathrm{N}$ pela planta foi de 82,5 e $59,9 \%$ do $\mathrm{N}$ aplicado das fontes $\mathrm{SA}$ e $\mathrm{U}$, respectivamente. Estudando a distribuição do $\mathrm{N}$ fertilizante na planta, Villas Boas et al. (2005) verificaram, em casa de vegetação, maior quantidade de N-SA (29 \%) no caule de milho que do N-U (23 \%). Essa expressiva recuperação de $\mathrm{N}$ aplicado em présemeadura (com ênfase no SA) indica que não foi a remineralização do $\mathrm{N}$-imobilizado ocorrida em fases anteriores a 11-12 folhas a responsável por essa maior recuperação (Quadro 2), e sim a provável permanência de $\mathrm{N}$ fertilizante em forma mineral nas camadas de influência do sistema radicular. Num solo muito argiloso, como o utilizado neste estudo, seria provável de ocorrer, sendo mais improvável num solo de textura média ou arenosa, onde a lixiviação provavelmente passaria a ter maior importância. Neste estudo, a eficiência de recuperação de $\mathrm{N}$ (N total absorvido pela fitomassa/Nfa) à colheita, segundo Hofmann \& Cleemput (2004), foi de 2,75 e 2,66 $\mathrm{kg} \mathrm{kg}^{-1}$ de N-SA e $\mathrm{N}-\mathrm{U}$, respectivamente.

Na colheita, em média, a MMS total e a MMSgrãos foram de 20,4 e 10,1 $\mathrm{t} \mathrm{ha}^{-1}$, respectivamente, e de $219,9 \mathrm{~kg} \mathrm{ha}^{-1}$ de $\mathrm{N}$ total extraído pela planta, quando aplicado SA, e de 20,8; 8,99 e 213,1 $\mathrm{kg} \mathrm{ha}^{-1}$, respectivamente, quando aplicada U. Portanto, para produção de uma tonelada de grãos utilizando-se SA, foram extraídos 21,9 $\mathrm{kg}$ de $\mathrm{N}$ e produzidos 2,03 t de MMS. Empregando U, foram 23,7 kg de $\mathrm{Ne} 2,32 \mathrm{Mg}$ de MMS. Foram necessários, portanto, menos $\mathrm{N}$ e MMS para produzir uma tonelada de grãos, quando utilizado SA em pré-semeadura, que U. Esses valores são semelhantes aos apresentados por Cantarella et al. (2005), citando diversos autores. A utilização de ${ }^{15} \mathrm{~N}$ tornou possível calcular a quantidade de $\mathrm{N}$ fertilizante extraído pela planta inteira e a quantidade absorvida pela planta para produção de uma tonelada de grãos. O NppSA da planta inteira (parte aérea, grãos e raiz) foi de $63,8 \mathrm{Mg} \mathrm{ha}^{-1}$ para produzir $10,1 \mathrm{Mg} \mathrm{ha}^{-1}$ de grãos. Portanto, 30,0 \% de N [(6,34/ $21,9) \times 100$ ] foi utilizado para produção de uma tonelada de grãos, e para a U foram $22,2 \%$ do $\mathrm{N}$ total $[(5,26 / 23,7) \times 100]$. Esses resultados mostram que a proporção do N-SA foi superior à de N-U para a produção de uma tonelada de grãos.

\section{$\mathrm{N}$-imobilizado no solo (Nispf) e N-planta proveniente do fertilizante (Nppf) aplicado em cobertura na cultura de milho}

A mesma abordagem efetuada para aplicação dos fertilizantes em pré-semeadura foi adotada para os 
adubos aplicados em cobertura. Observou-se que as determinações de Nispf efetuadas nos estádios de 1112 folhas, florescimento e colheita foram inferiores a $10 \mathrm{~kg} \mathrm{ha}^{-1}$ do $\mathrm{N}$ aplicado (<12,5 \%) (Quadro 3). Nas condições deste estudo e de modo similar ao ocorrido

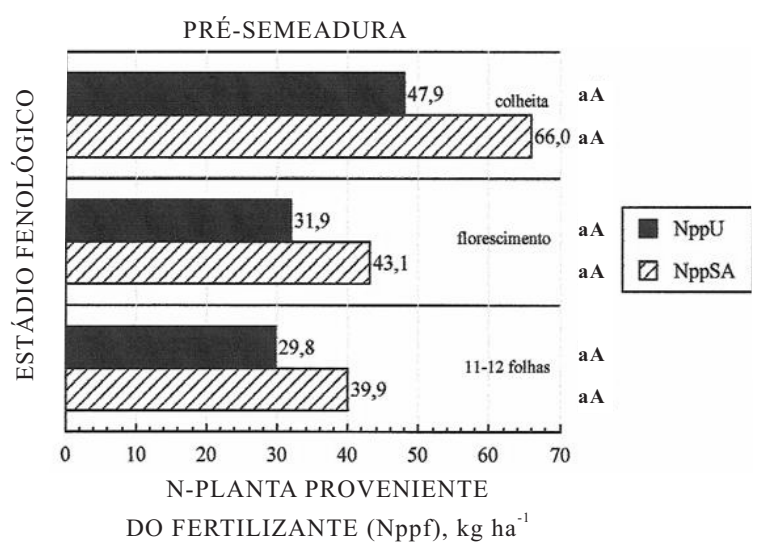

Figura 3. Nitrogênio na planta proveniente do sulfato de amônio $(N p p S A)$ e da uréia $(N p p U)$ aplicado em pré-semeadura, acumulado em três estádios da cultura de milho na safra 2000/2001, em sistema plantio direto. DMS (entre fontes - letras minúsculas $)=28,0 \mathrm{~ns}$. DMS (entre épocas - letras maiúsculas $)=20,7 \mathrm{~ns} . \mathrm{CV}(\%)=38,2$. no ano anterior, o processo de imobilização, já num período regular de pluviosidade, não foi significativo a ponto de concorrer pelo nutriente com a planta. Cabe salientar que entre as fontes, também como ocorrido no ano anterior, houve tendência de menor imobilização do N-SA que do N-U.

Os ajustes das curvas de regressão do Nispf de acordo com o ciclo da cultura (Figura 4) mostram claramente essa tendência, nos dois anos consecutivos, para SA e U. Tomando-se como exemplo o tempo de 60 DAA, logo após a fase de florescimento, e considerando as duas safras consecutivas, 7,1 e $3,1 \mathrm{~kg} \mathrm{ha}^{-1}$ de Nispf foram estimados de U e SA, respectivamente.

$\mathrm{N}$-planta proveniente do fertilizante (Nppf), eficiência de utilização de $\mathrm{N}$-planta proveniente do fertilizante ( $E U N p p f)$ e eficiência de recuperação de $\mathrm{N}$-planta proveniente do fertilizante (ERNppf) aplicado em cobertura na cultura de milho

A aplicação dos fertilizantes em cobertura (Figura 5) mostrou maior eficiência de recuperação pela planta em todos os estádios, em relação à présemeadura (Figura 3). Até a colheita, o NppSA foi de $71,3 \mathrm{~kg} \mathrm{ha}^{-1}$ do $\mathrm{N}$ aplicado (eficiência de 89,1\%) e o $N p p U$, de 36,0 kg ha-1 (eficiência de 45,0 \%); tanto na pré-semeadura como na cobertura houve maior

Quadro 3. N total do solo proveniente do fertilizante (Ntspf), N mineral do solo proveniente do fertilizante (Nmispf), N-imobilizado no solo proveniente do fertilizante (Nispf) e fração do $\mathrm{N}$ fertilizante imobilizado após a aplicação em cobertura de sulfato de amônio e uréia, para a cultura do milho, em sistema plantio direto $^{(1)}$

\begin{tabular}{|c|c|c|c|c|c|c|c|c|c|c|}
\hline \multirow{2}{*}{ Época (estádio) } & \multirow{2}{*}{ N-total } & \multirow{2}{*}{$\begin{array}{c}\text { Concentração } \\
\text { de }{ }^{15} \mathrm{~N}\end{array}$} & \multicolumn{2}{|c|}{ Ntspf } & \multirow{2}{*}{$\begin{array}{l}\text { N-min. } \\
\text { Total }\end{array}$} & \multirow{2}{*}{$\begin{array}{c}\text { Concentração } \\
\text { de }{ }^{15} \mathrm{~N}\end{array}$} & \multicolumn{2}{|c|}{ Nminspf } & \multicolumn{2}{|c|}{ Nispf } \\
\hline & & & Concentração & Conteúdo & & & Concentração & Conteúdo & Concentração & Conteúdo \\
\hline $\mathrm{DAA}^{(2)}$ & $\mathrm{kg} \mathrm{ha}{ }^{-1}$ & atom. \% excesso & $\%$ do aplicado & kg ha & $a^{-1}-$ & Atom. \% excesso & $\%$ do aplicado & $\mathrm{kg} \mathrm{ha}^{-1}$ & $\%$ do aplicado & $\mathrm{kg} \mathrm{ha}^{-1}$ \\
\hline \multicolumn{11}{|l|}{ Sulfato de Amônio } \\
\hline 35 (11-12 folhas) & $235 \mathrm{aA}$ & 0,111 & 2,4 & $5,6 \mathrm{bA}$ & 2,6 aA & 0,509 & 11,0 & $0,3 \mathrm{bA}$ & 6,6 & 5,3 aA \\
\hline 51 (florescimento) & $166 \mathrm{aA}$ & 0,098 & 2,1 & $3,5 \mathrm{bA}$ & 2,0 aA & 0,334 & 7,2 & $0,2 \mathrm{aAB}$ & 4,1 & $3,3 \mathrm{bA}$ \\
\hline 129 (colheita) & $179 \mathrm{aA}$ & 0,102 & 2,2 & $3,9 \mathrm{aB}$ & 2,8 aA & 0,156 & 3,4 & $0,1 \mathrm{aB}$ & 4,8 & 3,8 aA \\
\hline \multicolumn{11}{|l|}{ Uréia } \\
\hline 35 (11-12 folhas) & 247 aA & 0,167 & 3,7 & 9,1 aA & 3,3 aA & 1,215 & 27,0 & 0,8 aA & 10,4 & 8,3 aA \\
\hline 51 (florescimento) & $167 \mathrm{aB}$ & 0,200 & 4,5 & 7,5 aA & $1,7 \mathrm{aB}$ & 0,310 & 6,9 & $0,1 \mathrm{aB}$ & 9,3 & $7,4 \mathrm{aAB}$ \\
\hline 129 (colheita) & $170 \mathrm{aB}$ & 0,087 & 1,9 & $3,2 \mathrm{aB}$ & $2,5 \mathrm{aAB}$ & 0,107 & 2,4 & $0,1 \mathrm{aB}$ & 3,9 & $3,1 \mathrm{aB}$ \\
\hline $\begin{array}{l}\text { DMS (entre fontes } \\
\text { para cada época) }\end{array}$ & 62 & & & 1,9 & 0,8 & & & 0,08 & & 3,5 \\
\hline $\begin{array}{l}\text { DMS (entre épocas } \\
\text { para cada fonte) }\end{array}$ & 76 & & & 2,3 & 0,9 & & & 0,10 & & 4,3 \\
\hline CV (\%) & 17,9 & & & 19,6 & 17,3 & & & 17,3 & & 37,1 \\
\hline
\end{tabular}

(1) As médias entre épocas para cada fonte, seguidas de letras maiúsculas iguais, não diferem significativamente pelo teste de Tukey a 0,05. As médias entre fontes para cada época, seguidas de letras minúsculas desiguais, diferem significativamente pelo teste de Tukey a 0,05\%. ${ }^{(2)} \mathrm{DAA}=$ dias após aplicação de sulfato de amônio e uréia. 

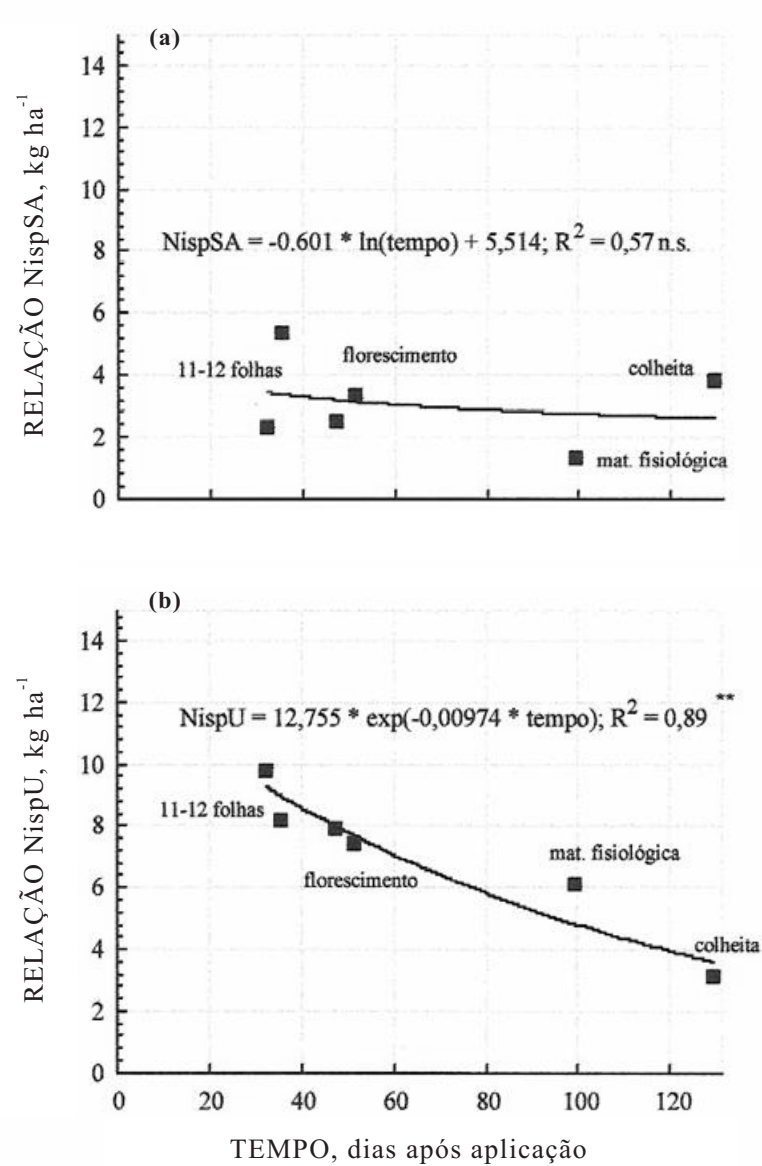

Figura 4. Nitrogênio imobilizado no solo proveniente do sulfato de amônio (NispSA) (a) e da uréia (NispU) (b), após a aplicação em cobertura na entrelinha das fileiras de plantas de milho, em duas safras consecutivas (1999-2001), em sistema plantio direto.

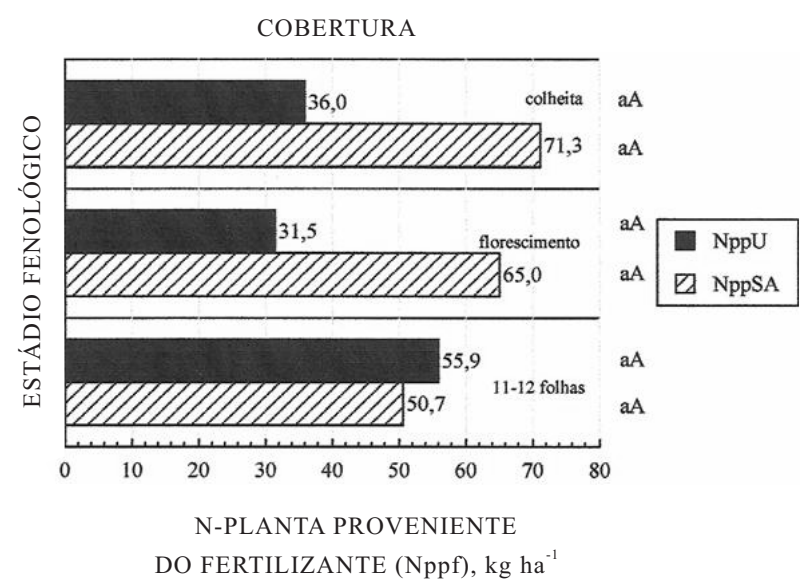

Figura 5. Nitrogênio na planta proveniente de sulfato de amônio $(N p p S A)$ e da uréia $(N p p U)$ aplicado em cobertura e acumulado em três estádios do ciclo da cultura de milho, na safra 2000/2001, em sistema plantio direto. DMS (entre fontes - letras minúsculas $)=36,6 \mathrm{~ns}$. DMS (entre épocas - letras maiúsculas $)=29,9 \mathrm{~ns}$. CV $(\%)=32,3$. recuperação de N-SA pela planta. Estudos realizados no Brasil com uso do isótopo ${ }^{15} \mathrm{~N}$ mostram que, em média, $85 \%$ do $\mathrm{N}$ fertilizante foi recuperado no sistema solo-planta (Lopes et al., 2004). A eficiência de recuperação de $\mathrm{N}$ pela planta foi de $3,36 \mathrm{~kg} \mathrm{~kg}^{-1}$, quando aplicado AS, e de $2,5 \mathrm{~kg} \mathrm{~kg}^{-1}$, quando se aplicou U. Cantarella et al. (2003), em Latossolo Vermelho argiloso, em Ribeirão Preto-SP, semeando milho após aveia-preta nas safras 1999/2000 e 2000/2001, aplicaram $80 \mathrm{~kg} \mathrm{ha}^{-1}$ de N-U antecipado 45 e 20 dias, nas respectivas safras ou em cobertura, e verificaram que até a fase de seis folhas pouco $\mathrm{N}$ aplicado antecipado havia sido absorvido pelo milho e que houve ativa absorção do $\mathrm{N}$ fertilizante quando aplicado tanto antecipado como em cobertura - resultados similares aos registrados neste estudo. Também registraram maior quantidade de $\mathrm{N}$ fertilizante na planta quando o $\mathrm{N}$ foi aplicado em cobertura, em relação ao adubo antecipado (66,4 e 48,3 \% de N-U recuperado na planta inteira quando aplicado em cobertura, em relação à semeadura, respectivamente, na safra 1999/2000, e 63,0 e 58,5 \%, respectivamente, na safra 2000/2001). Ernani et al. (2005) constataram, em solos argilosos com alto teor de $\mathrm{MO}$, que a imobilização de $\mathrm{N}$ decorrente da adição de aveia-preta é pequena, inferior ao $\mathrm{N}$ mineralizado desse resíduo ou da MO nativa, não havendo resposta à adição de fertilizantes nitrogenados.

Nessa época de aplicação dos adubos, à colheita, em média, a MMS total e a MMS-grãos foram de 23,3 e 12,2 $\mathrm{t} \mathrm{ha}^{-1}$, respectivamente, e de $269,3 \mathrm{~kg} \mathrm{ha}^{-1} \mathrm{de}$ $\mathrm{N}$ total extraído pela planta, quando se aplicou AS, e 20,05; 8,60 e 199,7, respectivamente, quando aplicada U. Portanto, para produção de uma t de grãos utilizando SA, foram extraídos $22,1 \mathrm{~kg}$ de $\mathrm{N}$ e produzidos 1,91 t de MMS. Empregando U, foram $23,2 \mathrm{~kg}$ de $\mathrm{N}$ e 2,33 t de MMS. Em cobertura, de modo similar ao verificado em pré-semeadura, quantidade menor de N e MMS foi necessária para produzir uma t de grãos, quando utilizado SA. Comparando esses valores com os relatados em présemeadura, pode-se observar que foram similares, razões pela qual o genótipo do material estaria, muito provavelmente, prevalecendo sobre o manejo do fertilizante. Nessa época de aplicação, o N-SA contribuiu com $26,3 \%$ de $\mathrm{N}$ total $[(5,82 / 22,1)$ x 100$]$ para produção de uma t de grãos, e a U contribuiu com 20,1\% do $\mathrm{N}$ total [(4,67/23,2) x 100]. Esses resultados evidenciam a dificuldade de se obter diferença significativa em estudos de fontes, doses, épocas e formas de aplicação de $\mathrm{N}$ quando a participação do $\mathrm{N}$ fertilizante é relativamente pequena em relação à do N-nativo de solo.

\section{Razão de Nppf/Nispf das fontes uréia e sulfato de amônio aplicadas em pré-semeadura e cobertura na cultura de milho}

A avaliação quantitativa do Nppf e Nispf para as duas épocas permitiu calcular a razão $N p p f / N i s p f$ 
(Figura 6) e já utilizado no trabalho anterior (Lara Cabezas et al., 2005). Nesta figura, observam-se os valores calculados nos estádios de 11-12 folhas e florescimento, em duas safras consecutivas (1999/ 2001), da aplicação em pré-semeadura e cobertura das fontes SA e U. Em ambas as épocas, o SA apresentou valores significativos superiores aos da U. Na média das duas safras, em pré-semeadura (Figura 6a), $8,9 \mathrm{~kg} \mathrm{ha}^{-1}$ de N-SA foram absorvidos pela planta para cada quilo de $\mathrm{N}$-imobilizado dessa fonte, na profundidade de $0-10 \mathrm{~cm}$ (local de influência do adubo aplicado); para a U, foram $4,5 \mathrm{~kg} \mathrm{ha}^{-1} \mathrm{de} \mathrm{N}$. A relação mais estreita verificada com U coloca em evidência indiretamente que o $\mathrm{N}$ desta fonte foi mais imobilizado

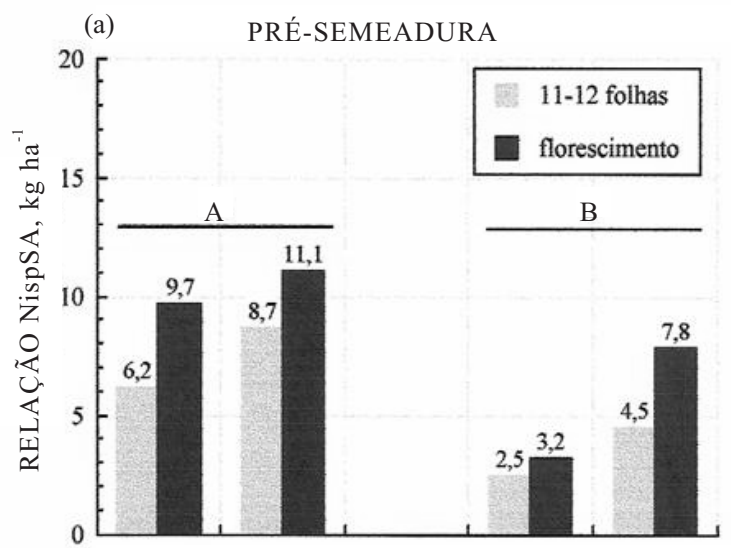

(b) COBERTURA

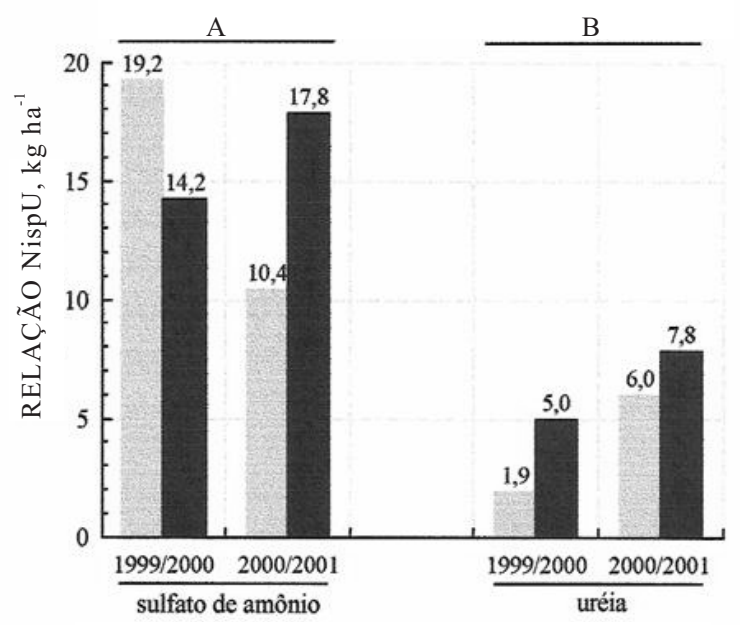

SAFRAS 1-999-2001

Figura 6. Razão de Nppf/Nispf após a aplicação de sulfato de amônio e uréia em pré-semeadura (a) e em cobertura (b) nos estádios de 11-12 folhas e florescimento, em duas safras consecutivas (1999-2001), na cultura de milho em sistema plantio direto. Médias seguidas de letras maiúsculas desiguais, entre fontes para cada época, diferem significativamente pelo teste de Mann-Whitney $(P=0,05)$. que o N-SA. Para condições climáticas diferentes, quanto a freqüência e quantidade de chuva e condições similares de solo e manejo da cultura antecessora (tipo e adensamento de palha), esses resultados indicam que as fontes reagem diferentemente em relação ao processo de imobilização.

Empregando o método de Araújo et al. (2005), que estimaram o $\mathrm{N}$ mineralizado e absorvido por plantas de trigo $(\mathrm{N}$ mineralizado $=\mathrm{N}$ total planta $-\mathrm{Nppf})$, os resultados mostraram para o estádio de 11-12 folhas, tanto em pré-semeadura como em cobertura, maiores valores de $\mathrm{N}$ mineralizado e absorvido pela planta quando aplicado SA, em relação a U: 127,9 e $98,1 \mathrm{~kg} \mathrm{ha}^{-1}$ em pré-semeadura e 157,0 e $99,9 \mathrm{~kg} \mathrm{ha}^{-1}$ em cobertura. Tanto direta como indiretamente, os resultados mostraram menor imobilização de $\mathrm{N}$-solo e $\mathrm{N}$ fertilizante com a utilização de SA como fertilizante. Cabe salientar o efeito sinérgico entre N e S na formação protéica da planta, existindo uma estequiometria média de 34 átomos de $\mathrm{N}$ para cada átomo de S (Malavolta et al., 1997), sendo estimulada a maior absorção de $\mathrm{N}$ pela planta na presença de $\mathrm{S}, \mathrm{o}$ que poderia estar afetando a imobilização do N-SA. $\mathrm{Wu}$ et al. (1995), incubando solo com ${ }^{35} \mathrm{~S}_{-} \mathrm{SO}_{4}{ }^{2-}$, glicose, $\mathrm{N}$ e resíduos de plantas durante 102 dias, mostraram que a adição de $\mathrm{N}$ incrementou a mineralização de S-orgânico, aumentando a disponibilidade de S-sulfato, o que estaria favorecendo a absorção de ambos os nutrientes pela planta.

Para a aplicação do N em cobertura (Figura 6b), a tendência dos resultados foi similar à observada em pré-semeadura. Nessa situação, houve aumento do NppSA e NppU em relação ao $\mathrm{N}$ fertilizante imobilizado. Para cada quilo de N-imobilizado no local de aplicação, 15,4 e 5,2 kg ha-1 de N-SA e N-U foram assimilados pela planta. Nesse caso, os resultados mostram que a imobilização afetou menos a recuperação de $\mathrm{N}$ fertilizante pela planta, com maior ênfase no SA.

\section{Evolução do $\mathrm{pH}$ e razão $\mathrm{C} / \mathrm{N}$ no sulco de adubação localizado na entrelinha das plantas de milho}

Em pré-semeadura (Figura 7a), houve importante aumento do $\mathrm{pH}$ logo após a aplicação da U (22 DAA), atingindo valor próximo a $\mathrm{pH} 7,0$. Aumentos de $\mathrm{pH}$ no solo pela aplicação de U foram observados por outros autores (Silva \& Vale, 2000; Barbosa Filho et al., 2004). Segundo mostrado por Longo \& Melo (2005), o aumento na concentração de substrato $\left(\mathrm{NH}_{4}{ }^{+}\right)$estaria ativando a urease do solo, a qual apresenta atividade máxima entre $\mathrm{pH}$ 6,5 até 9,0. $\mathrm{Em} \mathrm{pH} \mathrm{5,2,} \mathrm{típico} \mathrm{de}$ solos tropicais, esses autores erificaram atividade de urease 42 a $44 \%$ da máxima. Ao longo do ciclo da cultura, o pH apresentou tendência de diminuição, ficando estabilizado em torno de $\mathrm{pH}$ 6,0 até a colheita. A biomassa de solo poderia ter imobilizado S-orgânico oxidado, devido ao aumento de $\mathrm{pH}$ proveniente da MO, como assinalam Horowitz \& Meurer (2005). Por sua 
vez, o SA não mostrou maior variação ao longo do ciclo da cultura, flutuando entre 5,0 e 5,5 - valor de $\mathrm{pH}$ determinado em ausência de fertilizante. A permanência por maior tempo do $\mathrm{N}$ fertilizante no local da aplicação devido ao umedecimento incipiente do solo deve ter favorecido a maior imobilização de $\mathrm{N}$ e S pela biomassa de solo, em detrimento da nitrificação e acidificação do meio. Isso já foi comentado por Rosolem et al. (2003) em estudo da dinâmica de N; em razão da calagem e palha na superfície de solo, a incorporação à biomassa microbiana estaria neutralizando o efeito acidificante do fertilizante amoniacal. Ainda, em um solo com SPD já estabelecido, apesar dos problemas de manejo quanto a manter cobertura de solo média anual acima de $6 \mathrm{t} \mathrm{ha}^{-1}$, poderia haver aumento no consumo de $\mathrm{H}^{+}$, ou complexação do $\mathrm{Al}^{3+}$ com compostos orgânicos, diferentemente do sistema convencional, em que

(a)

$(13,1)(15,1)$ $(12,6)(14,4) \quad(17,5)$

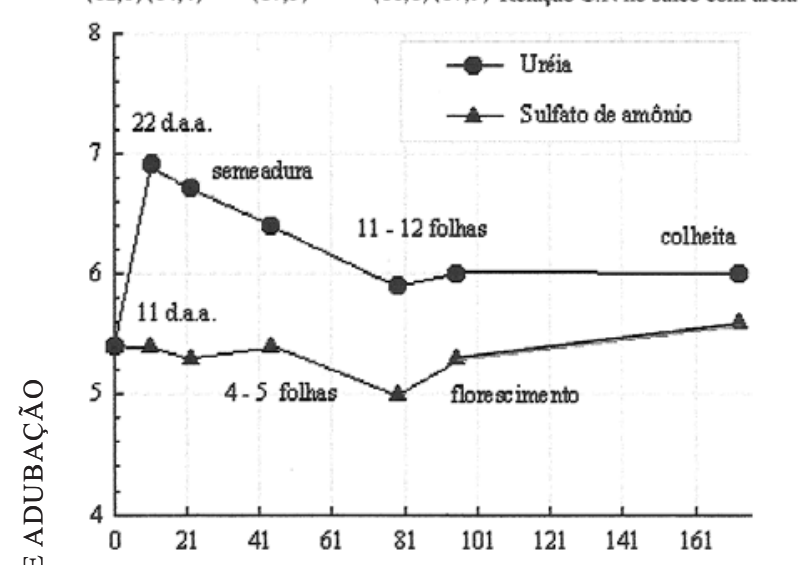

(b)

COBERTURA

$(18,9)(18,4)$ Relação C:N no sulco com SA

$(18,2) \quad(16,4)$ Relação C:N no sulco com uréia

3

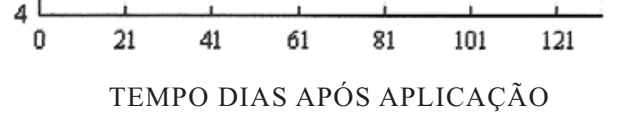

Figura 7. Variação do pH e relação C:N no sulco de adubação com aplicação de uréia e sulfato de amônio em pré-semeadura (a) e em cobertura (b) na cultura de milho (safra 2000/2001), em sistema plantio direto. haveria acidificação de solo pelo uso de fertilizantes amoniacais (uréia ou sulfato de amônio), que geram $\mathrm{H}^{+}$ao serem nitrificados. Theodoro et al. (2003) verificaram essa ocorrência, comparando sistemas de produção de cafeeiro orgânico com cobertura vegetal permanente, em relação ao sistema convencional de produção. A relação C:N sob o efeito dos fertilizantes U e SA aplicados em pré-semeadura mostrou-se inicialmente estreita aos 11 DAA $(12,6$ e 13,1), respectivamente, evoluindo para valores maiores $(17,9$ e 18,3) até o estádio de florescimento. O aumento da razão de acordo com o ciclo da cultura indica que o $\mathrm{N}$ fertilizante saiu da região da aplicação tanto pelo deslocamento em subsuperfície em forma direta quanto por lixiviação após sua transformação via nitrificação ou devido à absorção pela cultura, como discutido anteriormente.

Em cobertura, os resultados de $\mathrm{pH}$ mostram-se diferentes à pré-semeadura (Figura $7 \mathrm{~b}$ ), influenciada pela regularização do umedecimento do solo, diluindo a concentração das fontes aplicadas, e pela presença de sistema radicular no momento da aplicação dos fertilizantes. $\mathrm{O}$ pH no local da aplicação da U mostrou acréscimo atenuado, muito provavelmente pela rápida diluição do $\mathrm{N}$-amoniacal hidrolisado em presença da maior umidade em relação a pré-semeadura e sua assimilação pela cultura. Para o SA a tendência foi a esperada, acidificando o local de aplicação logo após a nitrificação, havendo menor chance para imobilização, com retorno ao valor nativo do solo, caracterizando a capacidade tamponante deste (Figura 7b).

\section{Produtividade de grãos}

A figura 8 mostra a produtividade de grãos. A testemunha apresentou produtividade significativamente inferior à dos tratamentos com aplicação de $\mathrm{N}$ em présemeadura ou cobertura, salientando a importância da suplementação de $\mathrm{N}$ para o milho nos estádios críticos de crescimento (Figura 8). Entre épocas de aplicação não houve diferença em produtividade, numa condição regular de pluviometria, como registrado por Cantarella et al. (2003) e Pöttker \& Wietholter (2000). Isso possibilita que o produtor do Cerrado tenha bons resultados com a antecipação da adubação, visto que a probabilidade de chuvas intensas é menor em relação ao Sul do País em solos de textura argilosa. Na safra 2001/2002, em Palmital (solo argiloso) e Votuporanga (solo arenoso), Cantarella et al. (2005) observaram queda de produtividade de milho quando aplicado N-pré-semeadura em relação à cobertura, devido a excessos hídricos que lixiviaram o $\mathrm{N}$ fertilizante. Em pré-semeadura houve maior produção de grãos com a utilização de SA em relação a U. Em média, foram produzidos $1.518 \mathrm{~kg} \mathrm{ha}^{-1}$ de grãos $(25,3$ sacas) a mais, com a utilização de SA. Em cobertura, a produtividade entre as fontes não mostrou diferença significativa. Em geral, a recuperação de Nppf até a colheita foi maior em cobertura que em pré-semeadura em ambas as fontes (Figura 3). A maior produtividade média obtida com SA, independentemente da 


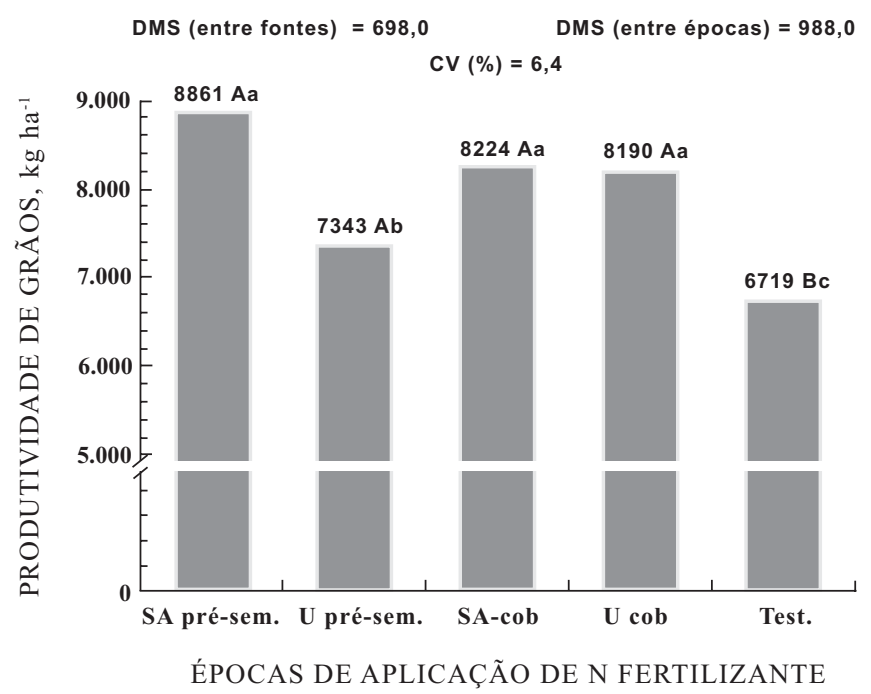

Figura 8. Produtividade de grãos após a aplicação em pré-semeadura e cobertura das fontes sulfato de amônio (SA) e uréia (U), na cultura de milho em sistema plantio direto. Médias seguidas de letras maiúsculas iguais entre épocas de aplicação não diferem significativamente pelo teste de Tukey a $0,05 \%$. Médias seguidas de letras minúsculas desiguais entre fontes diferem significativamente pelo teste de Tukey a $0,05 \%$.

época da aplicação ( $8.543 \mathrm{~kg}_{\mathrm{ha}}{ }^{-1}$ de grãos) em relação à U $\left(7.767 \mathrm{~kg} \mathrm{ha}^{-1}\right)$, pode também estar associada à maior razão NppSA/NispSA que à da U (Figura 5), evidenciando que a imobilização deve ter afetado menos a disponibilidade de $\mathrm{N}$ e de $\mathrm{S}$ para o milho que unicamente de $\mathrm{N}$ pela $\mathrm{U}$. Na safra anterior, também independentemente da época, o SA apresentou a maior produtividade, o que salienta a importância da presença de S na cobertura, em solos de Cerrado.

\section{CONCLUSÕES}

1. Houve imobilização significativa de $\mathrm{N}$ de ambas as fontes - uréia e sulfato de amônio - na sua aplicação em pré-semeadura do milho, no sulco de adubação, apresentando o SA maior rapidez na ciclagem do $\mathrm{N}$ imobilizado-mineralizado (turnover) e conseqüente maior absorção pelo milho.

2. Para cada kg de $\mathrm{N}$ fertilizante imobilizado no sulco de adubação, independentemente da época de aplicação das fontes, maior quantidade de $\mathrm{N}$ do SA foi recuperada pela planta entre os estádios de 11-12 folhas e florescimento.

3. Maior produtividade de grãos de milho foi obtida pela utilização do SA, independentemente da época de aplicação.

4. A aplicação de sulfato de amônio em présemeadura se apresenta mais vantajosa que a aplicação da uréia. A uréia é mais bem aproveitada pela cultura na aplicação em cobertura, quando a imobilização não se mostra significativa.

\section{AGRADECIMENTOS}

Os autores agradecem ao Convênio EmbrapaPetrobrás e à SN-Centro de Pesquisa e Divulgação do Sulfato de Amônio (Honeywell), pelo apoio financeiro. Também aos discentes do Instituto de Ciências Agrárias (ICIAG/UFU), que participaram na coleta de dados e em atividades pertinentes à instalação experimental.

\section{LITERATURA CITADA}

ARAÚJO, A.S.F.; TEIXEIRA, G.M.; CAMPOS, A.X.; SILVA, F.C.; AMBROSANO, E.J. \& TRIVELIN, P.C.O. Utilização de nitrogênio pelo trigo cultivado em solo fertilizado com adubo verde (Crotalaria juncea) e/ou uréia. Ci. Rural, 35:284-289, 2005.

BARBOSA FILHO, M.P.B.; FAGERIA, N.K. \& SILVA, O.F. Fontes e métodos de aplicação de nitrogênio em feijoeiro irrigado submetido a três níveis de acidez de solo. R. Ci. Agrotec., 28:785-792, 2004.

BARRIE, A. \& PROSSER, S.J. Automated analysis of lightelement stable isotopes by isotope ratio mass spectrometry. In: BOUTTON, T.W. \& YAMASAKI, S., ed. Mass spectrometry of soils. New York, Marcel Dekker, 1996. p.1-46.

BASSO, C.J. \& CERETTA, C.A. Manejo do nitrogênio no milho em sucessão a plantas de cobertura de solo, sob plantio direto. R. Bras. Ci. Solo, 24:905-915, 2000.

BROADBENT, F.E. \& TYLER, K.B. Effect of $\mathrm{pH}$ on nitrogen immobilization in two Californian soils. Plant Soil, 23:314322, 1965. 
BURGESS, M.S.; MEHUYS, G.R. \& MADRAMOOTOO, C.A. Nitrogen dynamics of decomposing corn residue components under three tillage systems. Soil Sci. Soc. Am. J. 66:1.350-1.358, 2002.

CANTARELLA, H.; DUARTE, A.P. \& ANDRADE, C.A. Manejo de nitrogênio e de matéria orgânica em milho no sistema plantio direto. In: FANCELLI, A.L. \& DOURADO NETO, D., eds. Milho: Tecnologia \& produção. Piracicaba, USP/ ESALQ/DPV, 2005. p.59-82.

CANTARELLA, H.; LERA, F.I.; BOLONHEZI, D.; LARA CABEZAS, W.A.R. \& TRIVELIN, P.C.O. Antecipação de $\mathrm{N}$ em milho em sistema de plantio direto usando ${ }^{15} \mathrm{~N}$. uréia. In: CONGRESSO BRASILEIRO DE CIÊNCIA DE SOLO, 24., Ribeirão Preto. 2003. Anais. Ribeirão Preto, Sociedade Brasileira de Ciência de Solo, 2003. CD-ROM

DORAN, J.W. Soil microbial and biochemical changes associated with reduced tillage. Soil Sci. Soc. Am. J., 44:765-771, 1980.

EMPRESA BRASILEIRA DE PESQUISA AGROPECUÁRIA EMBRAPA. Centro Nacional de Pesquisa de Solos. Sistema brasileiro de classificação de solos. Brasília, 1999. $412 \mathrm{p}$.

ERNANI, P.R.; SANGOI, L.; LECH, V.A. \& RAMPAZZO, C. A forma de aplicação da uréia e dos resíduos vegetais afeta a disponibilidade de nitrogênio. Ci. Rural, 35:360-365, 2005.

FLOSS, E.L. Aveia, um sustentáculo do sistema de semeadura direta. R. Plantio Direto, 72:14-18, 2002.

FRANCIS, D.D.; DORAN, J.W. \& LOHRY, R.D. Immobilization and uptake of nitrogen to corn as starter fertilizer. Soil Sci. Soc. Am. J., 57:1023-1026, 1993.

HASADA, A.; SOFERA, M.; MOLINAB, J.A.E.; BARAKB, P. \& CLAPPB, C.E. Assimilation of nitrogen by microbial population: $\mathrm{NH}_{4}^{+}$versus organic N. Soil Biol. Biochem., 24:137-143, 1992.

HOFMAN, G. \& CLEEMPUT, O.V. Soil and plant nitrogen. Access under < http://www.fertilizer.org/ifa/publicat/pdf/ 2004_ifa_soil_plant_nitrogen.pdf > Access date: Jan, 24, 2006.

HOROWITZ, N. \& MEURER, E.J. Uso de enxofre elementar como fertilizante. Inf. Agron., 112:4-7, 2005.

JACKSON, L.E.; SCHIMEL, J.P. \& FIRESTONE, M.K. Shortterm partitioning of ammonium and nitrate between plants and microbes in an annual grassland. Soil Biol. Biochem., 21:409-415, 1989.

JANSSON, S.L.; HALLAM, M.J. \& BARTHOLOMEW, W.V. Preferential utilization of ammonium over nitrate by micro-organisms in the decomposition of oat straw. Plant Soil, 6:382-390, 1955.

JAWSON, M.D. \& ELLIOT, L.F. Carbon and nitrogen transformations during wheat straw and root decomposition. Soil Biol. Biochem., 18:15-22, 1986.
LARA CABEZAS, W.A.R. \& LANGE, A. A cobertura morta aumenta a recuperação de $\mathrm{N}$ fertilizante na cultura de milho. R. Plantio Direto, 73:23-29, 2003.

LARA CABEZAS, W.A.R.; ARRUDA, M.R.; CANTARELLA, H.; PAULETTI, V.; TRIVELIN, P.C.O. \& BENDASSOLLI, J.A. Imobilização de nitrogênio da uréia e do sulfato de amônio aplicado em pré-semeadura ou cobertura na cultura de milho, no sistema plantio direto. R. Bras. Ci. Solo, 29:215-226, 2005.

LONGO, R.M. \& MELO, W.J. Hidrólise da uréia em latossolos: efeito da concentração de uréia, temperatura, $\mathrm{pH}$, armazenamento e tempo de incubação. R. Bras. Ci. Solo, 29:651-657, 2005.

LOPES, A.S.; WIETHOLTER, S.; GUILHERME, L.R.G. \& SILVA, C.A. Sistema plantio direto: Bases para o manejo da fertilidade do solo. São Paulo, ANDA, 2004. 115p.

MALAVOLTA, E.; VITTI, G.C. \& OLIVEIRA, S.A. Avaliação do estado nutricional das plantas: Princípios e aplicações. 2.ed. Piracicaba, POTAFOS, 1997. 319p.

MALHI, S.S.; GRANT, C.A.; JOHNSTON, A.M. \& GILL, K.S. Nitrogen fertilization management for no-till cereal production in the Canadian Great Plains: A review. Soil Till. Res., 60:101-122, 2001.

MORITSUKA, N.; YANAIC, J.; MORIB, K. \& KOSAKIC, T. Biotic and abiotic processes of nitrogen immobilization in the soil-residue interfase. Soil Biol. Biochem., 36:11411148,2004

OLIVEIRA, I.P.; ROSA, S.R.A.; KLUTHCOUSKI, J.; AIDAR, H. \& COSTA, J.L. Palhada no sistema Santa Fé. Inf. Agron., 93:6-9, 2001.

PÖTTKER, D. \& WIETHOLTER, S. Antecipação da aplicação de nitrogênio em milho. In: REUNIÃO BRASILEIRA DE FERTILIDADE DO SOLO E NUTRIÇÃO DE PLANTAS, 24.,2000, Santa Maria. Fertibio2000. Biodinâmica do solo. Santa Maria, SBCS/SBM, 2000. p.110-110.

PÖTTKER, D. \& WIETHOLTER, S. Épocas e métodos de aplicação de nitrogênio em milho cultivado no sistema plantio direto. Ci. Rural, 34:1015-1020, 2004.

RAIJ. B. van; ANDRADE, J.C.; CANTARELLA, H. \& QUAGGIO, J.A. Análise química para avaliação da fertilidade de solos tropicais. Campinas, Instituto Agronômico, 2001. 285p.

RECOUS, S.; FRENEAU, C.; FAURIE, G. \& MARY, B. The fate of labelled ${ }^{15} \mathrm{~N}$ urea and ammonium nitrate applied to a winter wheat crop. I Nitrogen transformations in soil. Plant Soil, 112:205-214, 1988.

ROSOLEM, C.A.; FOLONI, J.S.S. \& OLIVEIRA, R.H. Dinâmica de nitrogênio no solo em razão da calagem e adubação nitrogenada, com palha na superfície. Pesq. Agropec. Bras., 38:301-309, 2003.

SÁ, J.C.M. Manejo de nitrogênio na cultura de milho no sistema plantio direto. Passo Fundo, Aldeia Norte, 1996. 23p. 
SANTOS, H.P.; LHAMBY, J.C.B.; AMBROSI, I. \& IGNACZAK, J.C. Sistemas de rotação de culturas para a região Sul do Brasil. Passo Fundo, Embrapa Trigo, 1999. (Comunicado Técnico Embrapa Trigo, 4)

SILVA, C.A. \& VALE, F.R. Disponibilidade de nitrato em solos brasileiros sob efeito da calagem e de fontes e doses de nitrogênio. Pesq. Agropec. Bras., 35:2461-2471, 2000.

SIMS, J.T. Nitrogen mineralization and elemental availability in soils amended with composted sewage sludge. J. Environ. Qual., 19:669-675, 1990.
THEODORO, V.C.A.; ALVARENGA, M.I.N.; GUIMARÃES, R.J. \& SOUZA, C.A.S. Alterações químicas em solo submetido a diferentes formas de manejo do cafeeiro. R. Bras. Ci. Solo, 27: 1039-1047, 2003.

VILLAS BOAS, R.L.; BOARETTO, A.E.; GODOY, L.J.G. \& FERNANDES, D.M. Recuperação do nitrogênio da mistura de uréia e sulfato de amônio por plantas de milho. Bragantia, 64:263-272, 2005.

WU, J.; O‘DONNELL, G. \& SYERS, J.K. Influences of glucose, nitrogen and plant residues on the immobilization of sulphate-S in soil. Soil Biol. Biochem., 27:1363-1370, 1995. 